\title{
MAGNETIC RESONANCE IMAGING IN MIDDLE CEREBRAL ARTERY INFARCT AND ITS CORRELATION WITH FUNCTIONAL RECOVERY
}

\author{
Neethu Tressa Jose1, Rajan Padinharoot², Vadakooth Raman Rajendran³, Geetha Panarkandy ${ }^{4}$ \\ 1 Junior Resident, Department of Radiodiagnosis, Government Medical College, Kozhikode. \\ 2 Professor, Department of Radiodiagnosis, Government Medical College, Kozhikode. \\ 3 Professor and HOD, Department of Radiodiagnosis, Government Medical College, Kozhikode. \\ ${ }^{4}$ Additional Professor, Department of General Medicine, Government Medical College, Kozhikode.
}

\section{ABSTRACT}

\section{CONTEXT}

Middle cerebral artery stroke is described as the sudden onset of focal neurological deficit due to brain infarction in the territory supplied by the MCA. Patients have variable recovery of neurological functions after MCA stroke, but knowledge of the time course and extent of recovery is limited. It will be beneficial to know the stroke patient's early outcome and association between MR imaging findings and the clinical outcome.

\section{AIMS}

To assess the extent of infarction in MCA stroke from the MRI brain taken within 48 hours of onset of stroke. To study the association between MRI findings and clinical outcome in MCA stroke.

\section{MATERIALS AND METHODS}

Fifty patients who presented with symptoms of MCA stroke within 24 hours in medicine casualty of Govt. Medical College, Kozhikode, from March 2014 to September 2015 were taken for study. MRI brain including diffusion weighted images and MR angiogram were taken within 48 hours. Neurological status at the time of admission and after seven days was assessed using GCS score. Correlation between MRI findings and early clinical outcome was studied.

\section{RESULTS}

Majority of patients with MCA stroke were in age group between 50-69 years. Ninety four percentage of patients had one or more comorbidities, of which hypertension was the most common one; $20 \%$ patients expired within 7 days. Neurological improvement after one week was seen only in 32\%; $60 \%$ of all deaths occurred in patients with age more than 70 years. Majority of patients (86\%) had infarct size less than 50\%. Infarct size and DW-ASPECTS showed significant correlation with neurological outcome and day 7 survival. M1 occlusion showed poor early outcome in MCA infarct.

\section{CONCLUSION}

Patients with larger area of infarct and M1 occlusion has poor immediate post infarct recovery. DW ASPECTS score can be used as a good method for assessing extent of MCA infarct. However, large scale study with large sample size are needed for definite conclusion.

\section{KEYWORDS}

MCA Infarct, DW ASPECTS, M1 Occlusion, Early Neurological Outcome.

HOW TO CITE THIS ARTICLE: Jose NT, Padinharoot R, Rajendran VR, et al. Magnetic resonance imaging in middle cerebral artery infarct and its correlation with functional recovery. J. Evolution Med. Dent. Sci. 2016;5 (70): 5071-5075,

DOI: $10.14260 /$ jemds/2016/1152

\section{INTRODUCTION}

Middle cerebral artery stroke is described as the sudden onset of focal neurological deficit due to brain infarction in the territory supplied by the MCA. Infarcts that occur within the distribution of this vessel lead to significant neurologic sequelae. Patients have variable recovery of neurological functions after MCA stroke, but knowledge of the time course and extent of recovery is limited.

Financial or Other, Competing Interest: None.

Submission 29-05-2016, Peer Review 20-07-2016,

Acceptance 26-07-2016, Published 31-08-2016.

Corresponding Author

Dr. Neethu Tressa Jose,

Andaseril House,

Anickadu P. O.,

Kottayam- District-686503,

Kerala.

E-mail: neethutreesajose@gmail.com

DOI: $10.14260 /$ jemds/2016/1152

\section{AIMS AND OBJECTIVES}

- To assess the extent of infarction in MCA stroke from the MRI brain taken within 48 hours of onset of symptom.

- $\quad$ To study the association between MRI findings and early clinical outcome in MCA Stroke.

\section{METHODS}

\begin{tabular}{|c|c|}
\hline $\begin{array}{c}\text { Study } \\
\text { Design }\end{array}$ & \multicolumn{1}{|c|}{ Diagnostic Test Evaluation } \\
\hline $\begin{array}{c}\text { Study } \\
\text { Setting }\end{array}$ & $\begin{array}{l}\text { All cases coming to medicine casualty with } \\
\text { symptoms of MCA stroke, Govt. Medical } \\
\text { College Kozhikode, Kerala, India }\end{array}$ \\
\hline $\begin{array}{c}\text { Study } \\
\text { Period }\end{array}$ & March 2014 to September 2015 \\
\hline $\begin{array}{c}\text { Study } \\
\text { Method }\end{array}$ & $\begin{array}{c}\text { All patients coming with symptoms of } \\
\text { MCA stroke had detailed clinical } \\
\text { evaluation with emphasis on possible }\end{array}$ \\
\hline
\end{tabular}




\begin{tabular}{|c|c|}
\hline & $\begin{array}{l}\text { risk factors. Initial GCS score was } \\
\text { calculated for those patients at the time } \\
\text { of admission. MRI scan including FLAIR, } \\
\text { diffusion weighted images and } \\
\text { angiogram was taken within } 48 \text { hours } \\
\text { for study subjects. Percentage of area } \\
\text { showing diffusion restriction in affected } \\
\text { MCA territory and DW-ASPECTS score } \\
\text { was used to assess the extent of infarct. } \\
\text { Treatment included anti-platelets and } \\
\text { anti-oedema measures. Early functional } \\
\text { recovery was assessed clinically using } \\
\text { Glasgow coma scale calculated on day } \\
\text { seven. MRI findings and clinical outcome } \\
\text { was compared and association between } \\
\text { two were studied }\end{array}$ \\
\hline $\begin{array}{c}\text { Sample } \\
\text { Size }\end{array}$ & $\begin{array}{l}50 \text { patients } \\
\text { All patients satisfying inclusion criteria were } \\
\text { included in the study }\end{array}$ \\
\hline $\begin{array}{c}\text { Inclusion } \\
\text { Criteria }\end{array}$ & $\begin{array}{l}\text { MRI brain taken within } 48 \text { hours of onset of } \\
\text { symptoms. } \\
\text { Age between } 18-80 \text { years }\end{array}$ \\
\hline $\begin{array}{c}\text { Exclusion } \\
\text { Criteria }\end{array}$ & $\begin{array}{l}\text { Patient with previous episode of major } \\
\text { stroke } \\
\text { Presence of intracerebral bleeds } \\
\text { Involvement of other vascular territory }\end{array}$ \\
\hline $\begin{array}{l}\text { MRI } \\
\text { Protocols } \\
\text { and } \\
\text { Imaging }\end{array}$ & $\begin{array}{l}\text { MRI with a } 1.5 \text { T MR system (GE HDXT), } 16 \\
\text { channel with } 18 \text { superconducting shim coil } \\
\text { and a dedicated } 8 \text { channel 13-element } \\
\text { phased-array brain coil with the patient } \\
\text { lying supine. The imaging protocols include } \\
\text { mainly axial T2 FLAIR, DWI and MRA }\end{array}$ \\
\hline $\begin{array}{l}\text { Statistical } \\
\text { Analysis }\end{array}$ & $\begin{array}{l}\text { Severity of MCA infarct assessed as } \\
\text { percentage and frequency. Clinical outcome } \\
\text { assessed as percentage and frequency. } \\
\text { Relation between MRI and clinical outcome } \\
\text { calculation done using incidence and relative } \\
\text { risk. Statistical test used is chi square test. P } \\
\text { value }<0.05 \text { will be taken as significant }\end{array}$ \\
\hline
\end{tabular}

\section{ETHICS}

The study was approved by the Institutional Research Committee and Ethics Committee of Government Medical College, Kozhikode, Kerala, India.

\section{STATISTICS}

The Null Hypothesis (H0) assumes that there is no association between the predictor and outcome variables in the study population. When we conclude that there is statistical significance, the $\mathrm{P}$ value tells us what the probability is that our conclusion is wrong when in fact $\mathrm{HO}$ is correct. The lower the $\mathrm{P}$ value, the less likely that our rejection of $\mathrm{H} 0$ is erroneous. By convention, most analysts will not claim that they have found statistical significance if there is more than a $5 \%$ chance of being wrong $(\mathrm{P}=0.05)$.

\section{RESULTS}

Majority of patients with MCA stroke were in age group between 50-69 years (54\%).

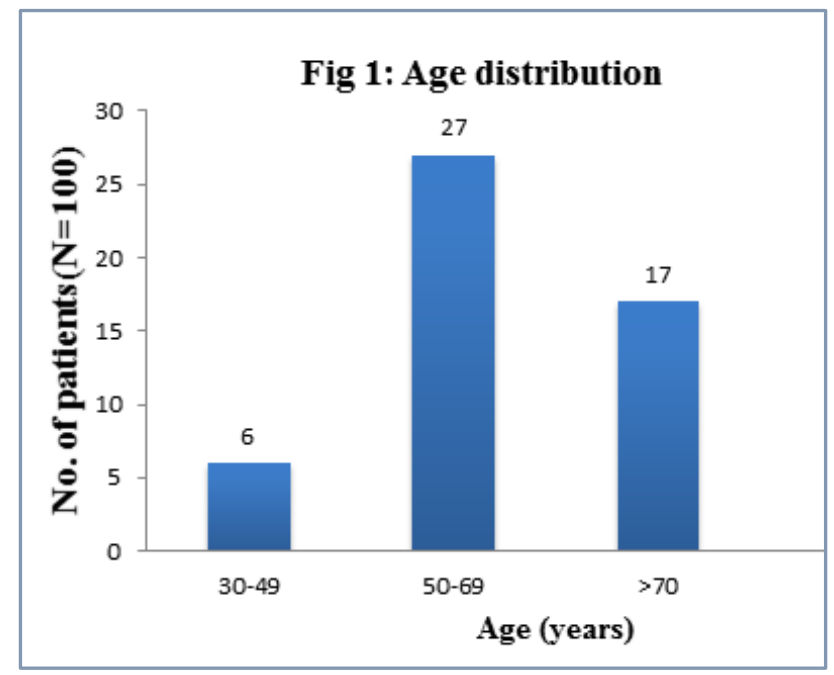

Incidence of MCA stroke was more among males (60\%)

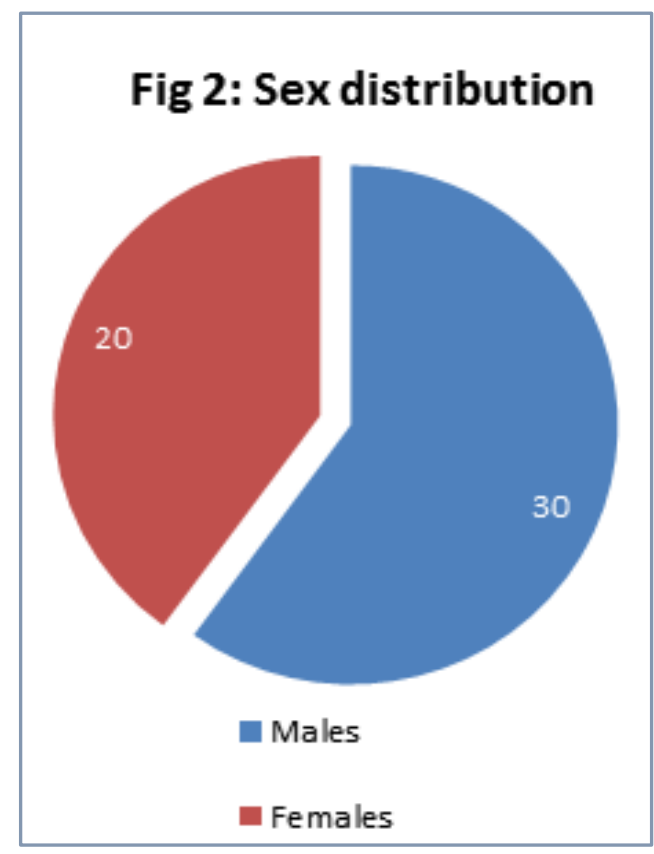

$94 \%$ of patients had one or more comorbidities.

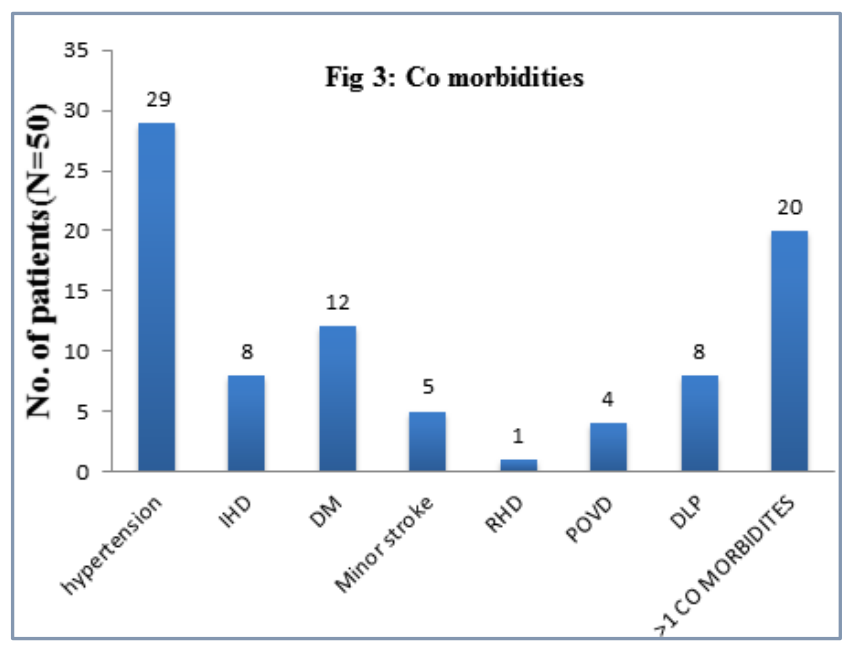

Most of the patients (54\%) had a moderate (9-12) GCS at the time of presentation; however, it did not have any correlation with 7-day outcome. 


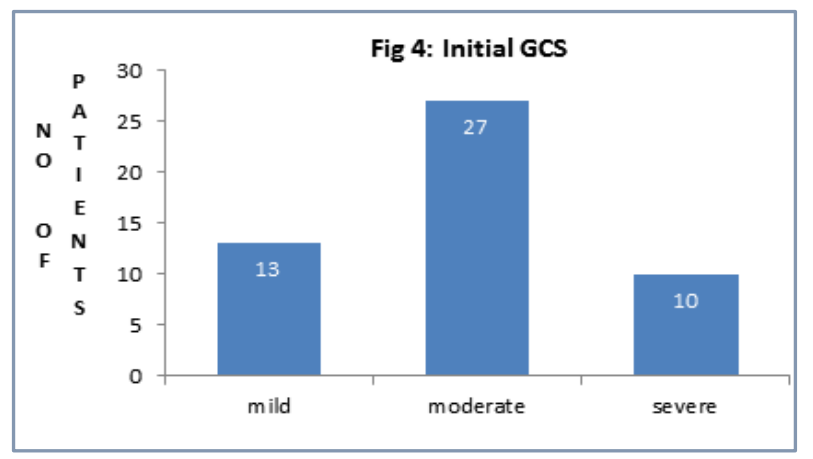

Only seven patients (14\%) had infarct size more than $50 \%$

\begin{tabular}{|c|c|c|c|c|c|}
\hline \multirow{2}{*}{$\begin{array}{c}\text { Infarct } \\
\text { Size } \\
\mathbf{5 5 0 \%}\end{array}$} & \multicolumn{4}{|c|}{ Neurological Status } & \multirow{2}{*}{ Total } \\
\cline { 2 - 5 } & Improving Day 7 Based on GCS & \\
\hline Yes & 0 & 1 & 1 & 5 & 7 \\
\hline No & 16 & 11 & 11 & 5 & 43 \\
\hline Total & 16 & 12 & 12 & 10 & 50 \\
\hline \multicolumn{5}{|c|}{ Table 2 } \\
\hline
\end{tabular}

Most of the patients (62\%) had an initial DWI-ASPECTS score 8-10.

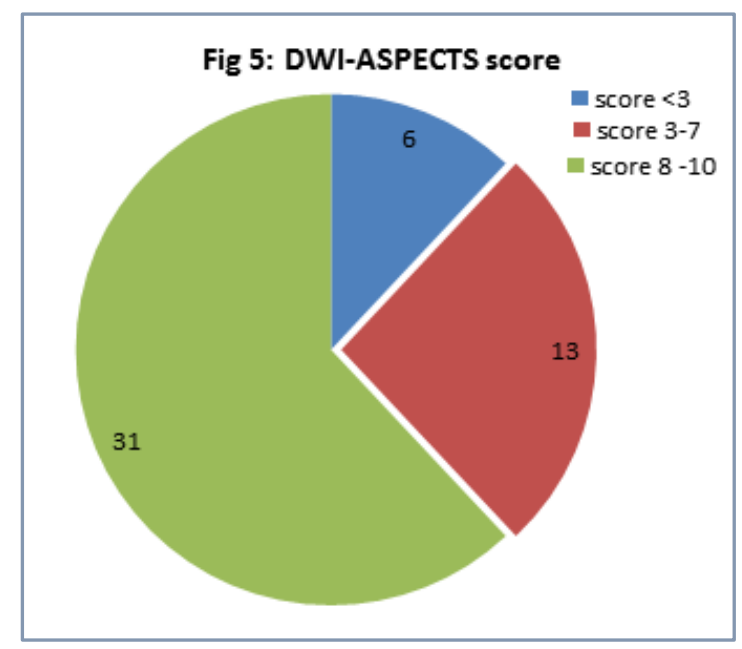

\begin{tabular}{|c|c|c|c|c|c|}
\hline \multirow{2}{*}{$\begin{array}{c}\text { DW Aspects } \\
\text { Score }\end{array}$} & \multicolumn{4}{|c|}{$\begin{array}{c}\text { Neurological Status } \\
\text { on Day 7 Based on GCS }\end{array}$} & \multirow{2}{*}{ Total } \\
\cline { 2 - 5 } & Improving & Static & Worsen & Death & \\
\hline DW $<3$ & 0 & 0 & 1 & 5 & 6 \\
\hline DW 3-7 & 5 & 7 & 1 & 0 & 13 \\
\hline DW 8-10 & 11 & 5 & 10 & 5 & 31 \\
\hline Total & $\mathbf{1 6}$ & $\mathbf{1 2}$ & $\mathbf{1 2}$ & $\mathbf{1 0}$ & $\mathbf{5 0}$ \\
\hline \multicolumn{7}{|c|}{ Table 3 } \\
\hline
\end{tabular}

Only 5 patients had M1 occlusion.

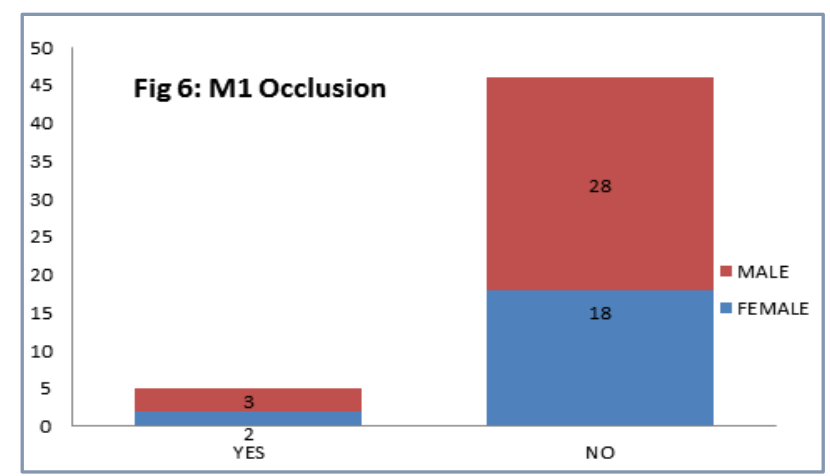

\begin{tabular}{|c|c|c|c|c|c|}
\hline \multirow{2}{*}{$\begin{array}{c}\text { M1 } \\
\text { Occlusion }\end{array}$} & \multicolumn{4}{|c|}{$\begin{array}{c}\text { Neurological Status on } \\
\text { Day 7 Based on GCS }\end{array}$} & \multirow{2}{*}{ Total } \\
\cline { 2 - 5 } & Improving & Static & Worsen & Death & \\
\hline Yes & 0 & 0 & 1 & 4 & 5 \\
\hline No & 16 & 12 & 11 & 6 & 45 \\
\hline Total & 16 & 12 & $\mathbf{1 2}$ & $\mathbf{1 0}$ & $\mathbf{5 0}$ \\
\hline \multicolumn{7}{|c|}{ Table 4 } \\
\hline
\end{tabular}

\section{DISCUSSION}

MRI findings and its correlation with early clinical recovery in fifty patients who presented to Govt. Medical College, Kozhikode, was studied.

Age

Age group of the patients in our study varied from forty two to seventy nine. The mean age was 63.2.

In a similar study by Dr. Dawn E Saunders and others on measurement of infarct size using MRI in prediction of prognosis of MCA infarct, mean age of patients with cortical MCA territory infarct was 66.5 yrs.

According to Asplund et al 2009, the chance of having a stroke approximately doubles for each decade of life after age 55 and while stroke is more common among the elderly, an increasing number of people under 65 are also having strokes.

In our study out of 10 deaths in the first 7 days, 6 were in the age group $>70$.

In general, according to the literature the risk of early fatality from stroke increases with age.

\section{Comorbidities}

94\% patients in our study had one or other comorbidities. Systemic hypertension was the most common among them (58\%) followed by diabetes (24\%) and ischaemic heart disease $(16 \%)$. More than two comorbidities were found in $40 \%$ patients. It has been proved in many studies before, that the most important modifiable risk factor for both cerebral infarction and intracerebral haemorrhage is hypertension. $1,2,3$ Some literature say diabetes is associated with a two- to fourfold increase in the risk of ischaemic stroke 4 and also with a poorer stroke outcome and increased stroke mortality. ${ }^{5}$

\section{Extent of Infarct}

It was calculated using percentage of infracted area and DWASPECTS score in diffusion weighted images.

It was proved in other studies like the one done by $\mathrm{C}$. Oppenheim et al that early Diffusion-Weighted Imaging (DWI) provides reliable quantitative information for the prediction of stroke patients at risk of malignant brain infarct. In our study, only $7(14 \%)$ patients had infarct size more than $50 \%$. Of the 7 patients who had infarct size more than $50 \%$, five $(71 \%)$ did not survive till day 7 , while two patients survived. Of the two patients survived, one showed worsening of neurological status while condition of other patient remained static. Infarct size showed statistical significance with neurological status on day 7.

In our study, DW ASPECTS score was used as an important method to assess the radiological severity of MCA infarct. Score has been divided into 3 groups (Score $<3,3-7,8-10$ ). Of the total 50 patients studied, six (12\%) patients had score $<3$, thirteen $(26 \%)$ patients had score $3-7$, thirty one (62\%) patients had score 8-10. Of the six patients who had DWASPECTS $<3$, five patients (83\%) did not survive till day 7 , only 
one patient survived whose condition was worsened. DWASPECTS score showed statistical significance with day 7 survival and early neurological outcome. There are no previous studies comparing early neurological outcome and extent of MCA infarct. However, various studies have proved that there is definite relation between long-term prognosis and volume of infarct.

In a study conducted by R. Gilberto González, it was suggested that all patients who had diffusion abnormality of greater than $72 \mathrm{~mL}$ had a poor outcome regardless of treatment. Clinical tradition holds that infarcts involving approximately $1 / 3$ of the MCA territory $(\sim 100 \mathrm{~mL})$ or greater have high likelihood of poor outcomes.

Also in another study by Dr. Dawn E Saunders and others it was shown that the volume of MCA infarction visible on MRI in patients within 72 hours of onset predicts outcome; the larger the infarct volume, the worse the outcome and patients with an initial infarct volume of less than $80 \mathrm{~cm}^{3}$ had a better outcome than patients with larger infarct volumes. In both these studies, long-term clinical outcome was assessed rather than early outcome.

In our study we did not calculate the infarct volume, instead DW ASPECTS score and percentage of infarcted area was assessed. We assessed short-term outcome of the patients, which is after 1 week. We did not do a long-term follow-up.

\section{M1 Occlusion}

MRA appears to provide information about intracranial arterial occlusion with a high rate of accuracy. In our study, MR Angiogram was done for all patients and patency of M1 segment of middle cerebral artery was assessed. Five patients showed M1 segment occlusion. Out of 5 patients who had M1 occlusion, 4 expired within 7 days; only one patient survived whose neurological status was worsened.

M1 occlusion showed statistical significance with day 7 survival ( $\mathrm{p}$ value $<.001$ ) and neurological outcome on day 7. In a study with 26 patients, Barber et $\mathrm{al}^{6}$ found that patients with absent M1 flow had larger lesion volumes, larger acute DWI lesion volumes, larger final infarct volumes and poorer clinical outcomes than the patients with M1 flow.

\section{Prognosis}

MCA infarct has poor prognosis according to our study; $20 \%$ patients expired within 7 days. Neurological improvement after one week was seen only in $32 \%$.

Most of the previous studies did long-term follow-up for patients. In one study, the percentages of independent patients after MCA stroke varied between $40 \%$ and $63 \%$. In some other studies, the percentage of survivor with a good recovery has been particularly low, i.e. $12 \%$ to $17 \%$.

It is presumed from our study that DW ASPECTS score and MR angiogram can be used as potential tools for diagnosing, prognostication and predicting the early neurological outcome in MCA infarct. There is a definite increase in immediate mortality among patients who have larger area of infarct.
Case 1: M1 occlusion present, extent of infarct $>50 \%$, DW ASPECTS $<3$, patient died within seven days.
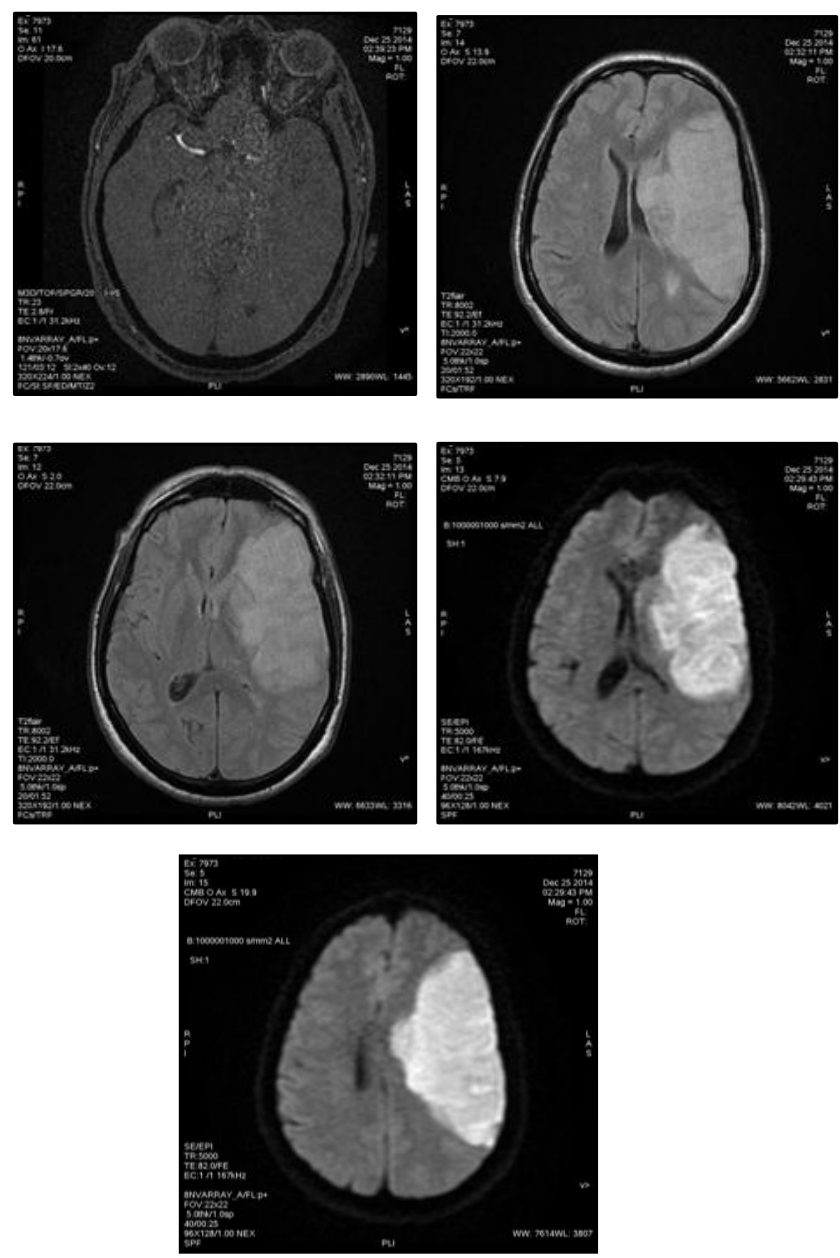

Case 2: Extent of infarct $<50 \%$, DW ASPECTS -7 , M1 occlusion absent, patient's neurological condition remained static.
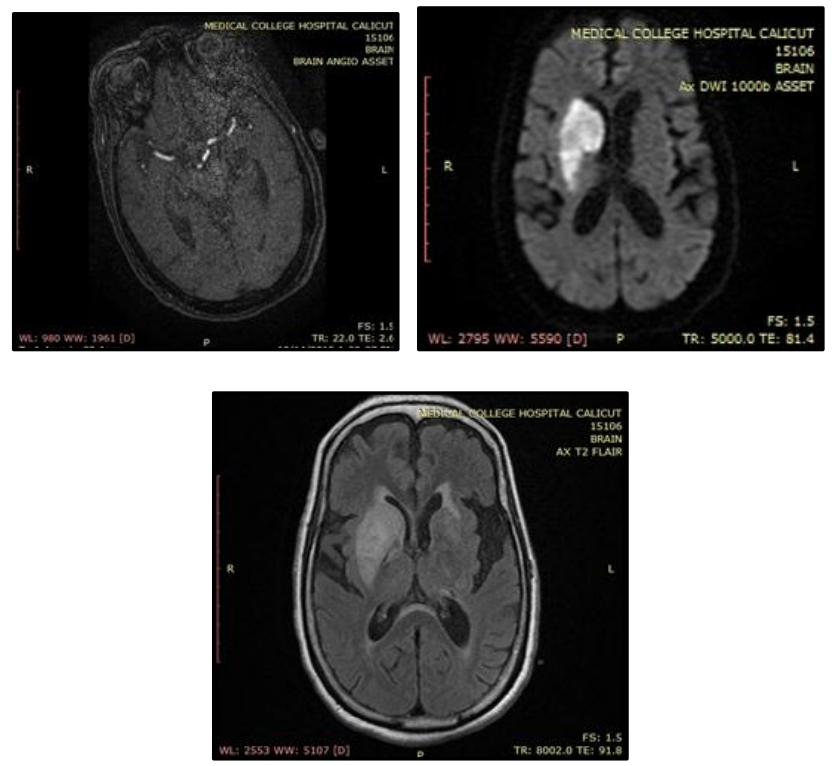
Case 3: DW ASPECTS -5, extent of infarct $>50 \%$, M1 occlusion absent, patient's neurological condition improved after 7 days.
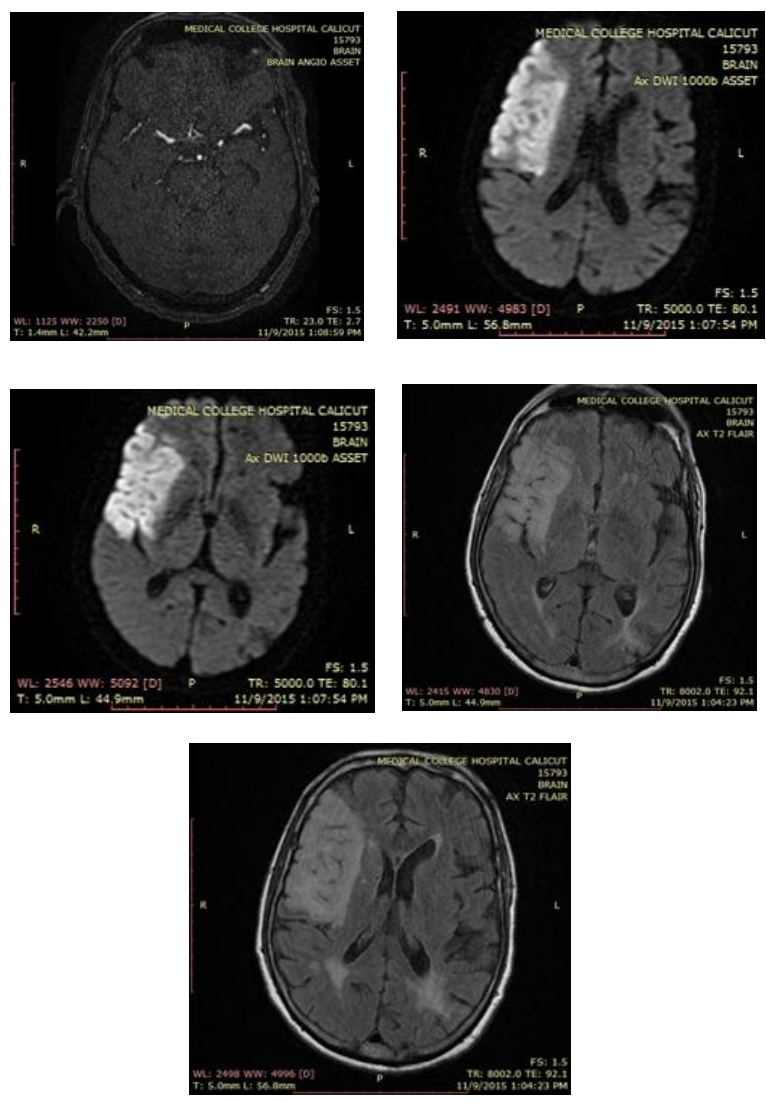

Case 4: DW ASPECTS $<3$, Extent of infarct $>50 \%$, M1 occlusion present, patient expired in seven days.
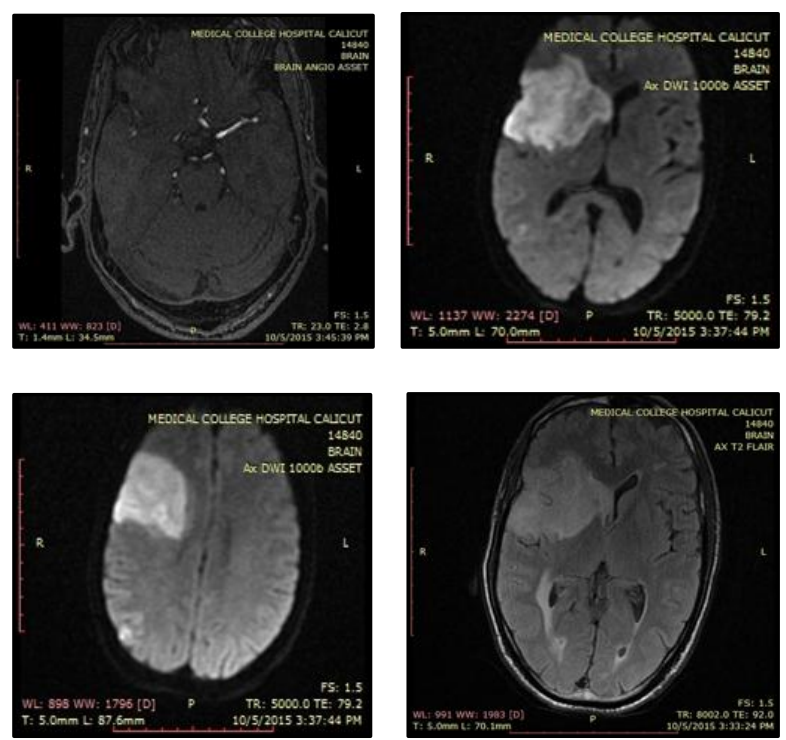

Case 5: DW ASPECTS-8, Extent of infarct $<50 \%$, M1 occlusion absent, patient's neurological condition improved.
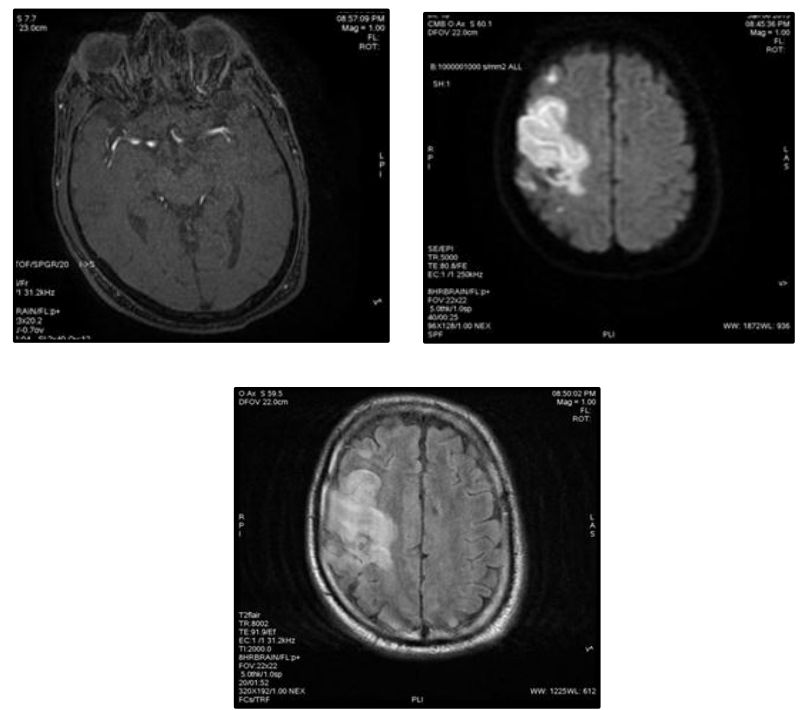

\section{REFERENCES}

1. Matsumoto N, Whisnant JP, Kurland LT, et al. Natural history of stroke in Rochester, Minnesota, 1955 through 1969: an extension of a previous study, 1945 through 1954. Stroke 1973;4(1):20-9.

2. Shafer SQ, Bruun B, Richter RW. The outcome of stroke at hospital discharge in New York City blacks. Stroke1973;4(5):782-6.

3. Adams GF, McComb SG. Assessment and prognosis in hemiplegia. Lancet 1953;265(6780):266-9.

4. Abbott RD, Donahue RP, MacMahon SW, et al. Diabetes and the risk of stroke. The Honolulu heart program. JAMA 1987;257(7):949-52.

5. Olsson T, Viitanen M, Asplund K, et al. Prognosis after stroke in diabetic patients. A controlled prospective study. Diabetologia 1990;33(4):244-9.

6. Barber PA, Davis SM, Darby DG, et al. Absent middle cerebral artery flow predicts the presence and evolution of the ischemic penumbra. Neurology 1999;52(6):112532.

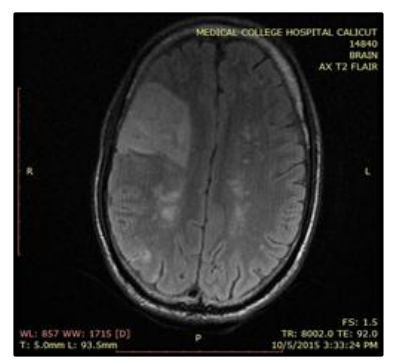

